Citation: J.M. Merchán, M. Cruz Alvarado, S. de Andrés, A. García-Matilla (2021) Cine para la Educación. Aprender de seis décadas de buenas experiencias educomunicativas. Media Education 12(1): 93-100. doi: 10.36253/ me-10142

Received: December, 2020

Accepted: March, 2021

Published: May, 2021

Copyright: @2021 J.M. Merchán, M. Cruz Alvarado, S. de Andrés, A. GarcíaMatilla. This is an open access, peerreviewed article published by Firenze University Press (http://www.fupress. $\mathrm{com} / \mathrm{me}$ ) and distributed under the terms of the Creative Commons Attribution License, which permits unrestricted use, distribution, and reproduction in any medium, provided the original author and source are credited.

Data Availability Statement: All relevant data are within the paper and its Supporting Information files.

Competing Interests: The Author(s) declare(s) no conflict of interest.

\section{Cine para la Educación. Aprender de seis décadas de buenas experiencias educomunicativas $^{1}$}

\author{
Cinema for Education. Learning from six decades of good \\ educommunicative experiences
}

José M. Merchán, M. Cruz Alvarado, Susana de Andrés, Agustín García-Matilla

Universidad de Valladolid, Valladolid (UVA)

E-mail: jmmb500@hotmail.com, mariacfruz.alvarado@uva.es, deanderesdelcampo@ gmail.com, agustingmatilla@gmail.com

\begin{abstract}
The Lumiere brothers, inventors of the cinematograph, did not think that it could be more interesting than a mere fairground attraction. However, at the beginning of the 20th century, the cinema was considered a medium of immense educational potential and it has been analyzed from multiple perspectives for its cultural value. Not only was George Meliés the first director to believe in the potential of cinema, simultaneously with the director Alice Guy, fictional cinema also began. Directors and theorists such as Griffith or Eisenstein, Riccioto Canudo, Henry Agel, Guido Aristarco, or André Bazin demonstrated the importance of the language of cinema from a practical perspective. The main objective here is to collect some of the most significant experiences in film pedagogy in the Spanish context, and discover with them the meaning and the sense of delving into this field and its importance in the real context of the screens that nourish the digital environment multimedia and transmedia. From the first film clubs, university experiences, pedagogical associations/groups, and the creation of educational centers, to audiovisual literacy actions for groups at risk of exclusion. As an example of the educational potential of cinema in isolation contexts, we will outline a recent case of its application in penitentiary institutions.
\end{abstract}

Keywords: Media Education, Cinema, Educommunication, prison, social communication.

Resumen. Los hermanos Lumiére, inventores del cinematógrafo, no pensaron que este pudiera ser más interesante que una mera atracción de feria. Sin embargo, comienzo desde el siglo XX, el cine fue secono un medio de inmenso potencial educador $\mathrm{y}$ ha

\footnotetext{
${ }^{1}$ Funding: This research is part of the work carried out within the Research Project "TRUTH AND ETHICS IN SOCIAL-NETWORKING WEBSITES. YOUNGTERS' PERCEPTIONS AND EDUCATIONAL INFLUENCE OF TWITTER, INSTAGRAM AND YOUTUBE. (INTERNETHICS), financed by the Spanish Ministry of Science, Innovation and Universities. (Ref. PID2019104689RB-I00
} 
sido extensiones perspectivas por su valor cultural. No solo George Meliés fue el primer director en creer en el potencial del cine, simultáneamente con la realizadora Alice Guy se inicia el cine de ficción. Directores y teóricos como Griffith o Eisenstein, Riccioto Canudo, Henry Agel, Guido Aristarco o André Bazin demostraron la importancia del lenguaje del cine desde una perspectiva práctica y. El principal objetivo aquí es algunas personas que las experiencias más significativas en pedagogía del cine del contexto español, y descubrir con ellas el significado y el sentido de profundizar en este campo, en su importancia en el contexto real de las pantallas que nutren el entorno digital multimedia y transmedia. Desde los primeros cineclubes, las experiencias universitarias, las asociaciones y colectivos pedagógicos o la creación de centros educativos, hasta acciones de alfabetización audiovisual para colectivos en riesgo de exclusión. Como ejemplo del potencial educador del cine en contextos de aislamiento, esbozaremos un caso reciente de su aplicación en instituciones penitenciarias.

Palabras clave: Educación en competencia mediática, cine, educomunicación, prisión, comunicación social.

\section{INTRODUCCIÓN METODOLÓGICA}

\subsection{Los orígenes de la pedagogía de la imagen en España}

Para comenzar, es imprescindible hacer mención a Guillermo Zúñiga, pionero del cine científico en nuestro país. Si bien, este repaso histórico pretende describir las experiencias más significativas relacionadas con el cine desde las perspectivas de la educación «en la imagen» y "con imágenes», resulta obligado rendir homenaje a este precursor ocupado en la divulgación del conocimiento científico a través del cine. Sus primeros trabajos se remontan a los años treinta del pasado siglo, con títulos pioneros como "Boda en Navalcán" (1932), "Marruecos" (1933) y "La vida de las Abejas" (1935). Zúñiga fue más que un divulgador, un profesional que abordó con rigor y ayudó a enriquecer los códigos específicos del cine científico, inspirando la creación de la Bienal de Cine Científico de la ciudad de Ronda.

En España, la educación en el cine cuenta con una larga trayectoria iniciada con la creación de los cineclubes, cuyos antecedentes son anteriores a la Guerra Civil. Si bien ya se habían realizado proyecciones en la Residencia de Estudiantes de Madrid de la mano de Luis Buñuel, el primer cineclub fue el Cine Club Español, dirigido por Ernesto Jiménez Caballero y Luis Buñuel, cuya primera sesión fue el 23 de diciembre de 1928 en el cine Callao de Madrid (Rodríguez-Fuentes, 2010). Además de las filiales que se crearon en otros lugares de España, destaca en Barcelona el Cineclub Mirador, con Sebastián Gash y Guillermo Díaz-Plaja. Un auge que prosiguió en los años treinta y del que Rodríguez Fuentes destaca también Proa Filmófon, Cinestudio 33, FUE, o Imagen.

En la primera posguerra, los cineclubes tuvieron un fuerte desarrollo en Cataluña de la mano de Miquel Porter Moix, intelectual polifacético, principal impulsor del movimiento de la Nova Cançó, que también tuvo el mérito de crear el primer Cine Club infantil de nues- tro país (Porter-Moix, 1964). En paralelo, se inicia la reconstrucción de los cineclubes de la mano del Sindicato Español Universitario (SEU), al principio con escaso éxito, pero dando lugar a partir de 1945, con la creación del Círculo de Escritores Cinematográficos (CERC), que, apoyado por intelectuales como Carlos Fernández Cuenca, Luis Gómez Mesa o Adriano del Valle, creó cineclubes por distintos lugares de la geografía española, experiencias que por lo general duraban muy poco, salvo en algunos casos.

Así sucedió en el caso de Zaragoza, cuyo cineclub se mantuvo durante 7 años exhibiendo films de gran calidad artística y prohibidos en el circuito comercial como "Náufragos" de Alfred Hitchcock, "Tormenta sobre México" de Sergei M. Eisenstein (1957) o "Napoleón" de Abel Gance. Esta iniciativa, en la que participaron nombres como Eduardo Ducay, Orencio Ortega Frisón, Manuel Rotellar, o Guillermo Fatás Ojuel, además de crear un modelo que sería utilizado después para extender el papel cultural del cine en otros lugares, construyó una experiencia global de aprendizaje sobre, en torno y a partir del cine, en la que había «una lógica coherente en los títulos expuestos,...sesiones especializadas en temas cinematográficos;... edición de los programas con fotografías» $y$ «...fichas completas de las películas, con sus correspondientes comentarios».

Ya en los cincuenta, en Castilla y León, el salmantino Basilio Martín Patino, que fuera después prestigioso director de cine, creaba en 1953 el cineclub de la Universidad de Salamanca, que dos años después acogería las Conversaciones Cinematográficas Nacionales que supondrían un antes y un después en el cine español. Desde 1962, la Cátedra de Cine de Valladolid inició una labor de divulgación bajo la dirección de José María Stahelin (1981). Labor extendida durante 57 ediciones convocando a centenares de personas interesadas y a estudiosos del lenguaje cinematográfico, de su historia y su proyección social. Profesores vinculados con las primeras ediciones de la Cátedra, como Cándido Fernández, publica- 
ron trabajos relacionados con la pedagogía del cine (Fernández, 1979). El seguimiento de todas las experiencias desarrolladas en España entre los años sesenta del siglo veinte y nuestros días, nos lleva a repasar las potencialidades del cine como medio para la educación. Es precisamente esa voluntad de promover la enseñanza del cine como actividad paralela a la educación formal reglada, lo que caracteriza a las primeras experiencias de incorporación del cine a la escuela.

En la década de los setenta el Servicio de Orientación de Actividades Para-escolares (SOAP) realizó una extraordinaria labor pionera en centros de Madrid, Barcelona y Vigo enseñando las posibilidades del lenguaje del cine a cientos de escolares y dándoles oportunidad de realizar sus propios cortometrajes en soporte súper $8 \mathrm{~mm}$. Era la primera vez que en España un equipo interdisciplinar abordaba la enseñanza del cine en la escuela desde una doble faceta, la formación de profesores en el lenguaje cinematográfico y su evolución histórica. Esta didáctica se completaba con la educación de las capacidades expresivas de los adolescentes en la construcción de sus historias y también daba oportunidad para que los propios escolares realizaran sus propias producciones en pequeños formatos. Todos los estudiantes tenían ocasión de pasar por las diferentes tareas que implicaba la realización de una película: guion, producción, realización, operación de cámara, montaje. Se trataba de la primera iniciativa en la que estudiantes de diferentes institutos de ciudades españolas se familiarizaban con las posibilidades creativas del cine, realizando sus propias historias. Los adolescentes eran los responsables últimos de sus producciones con ayuda de sus monitores.

Estudiar el contenido de las guías didácticas para profesores editadas entonces por el SOAP da idea de la dimensión del proyecto (Mendo et al., 1975). En los equipos de diseño del SOAP se integraron profesionales del cine, de la televisión y de la educación como Francisco Climent, Eduardo García Maroto (García-Maroto, 1988), Luis Matilla, Manuel Alonso (Alonso \& Matilla, 1980), Miguel Vázquez Freire o Pablo del Río, que hicieron posible un trabajo de extraordinaria relevancia.

Paralelamente, en el contexto catalán, el Colectivo Drac Magic desarrolló una experiencia de explotación didáctica del cine en diferentes áreas de conocimiento como las Humanidades, la Historia, la Historia del Arte, las áreas de Ciencias y de Ciencias Sociales, seleccionando aquellos títulos de especial relevancia en estas temáticas para su aprovechamiento didáctico en las escuelas. Marta Selva, Anna Solá y José Enrique Monterde fueron los creadores. A diferencia de la experiencia anterior, Drac Magic se especializó en la explotación didáctica del cine por áreas de conocimiento, pero también resultó una experiencia pionera continuadora de una tradición que en Cataluña se ha mantenido con gran solidez a lo largo de los años (Monterde et al., 2002).

\subsection{Experiencias pioneras en los festivales de cine}

La Oficina Permanente de Pedagogía de la Imagen (OPPI) marcó un hito dentro del Certamen Internacional de Cine para la Infancia y la Juventud de Gijón. Un Festival que llegó a ser el tercero del mundo en su especialidad, tras los de Moscú y Teherán. La OPPI convocó todos los veranos a comienzos de los años ochenta (de 1982 a 1984) a los mejores especialistas en pedagogía del cine y de la imagen tanto de España como de otros países de Iberoamérica.

Por su parte, "Pe De Imaxe", en La Coruña, fue una Iniciativa que profundizó en aspectos teóricos de la pedagogía de la imagen y del cine en particular (Vázquez-Freire, 1995), con la presencia de investigadores latinoamericanos como Mario Kaplún, Guillermo Orozco o Ismar de Oliveira, y de algunas de las voces más críticas del ámbito anglosajón como Len Masterman o Kathleen Tyner.

Otra iniciativa surgida a principios de los años noventa fue el Festival Cinema Jove, creado por el profesor Adolfo Bellido en Cheste (Valencia). Muchos jóvenes de toda España tuvieron ocasión de ver proyectadas sus películas en esta muestra en la que también se concedían premios y se alentaba el debate con los especialistas (Bellido, 1993). Enrique Martínez-Salanova (2010), Joan Ferrés (2014), Roberto Aparici (Aparici et al., 2006), Manuel González, Miguel Vázquez-Freire (1986), Juan Antonio Pérez-Millán (2014), Lluis, Rey, Aurora Maquinay (1984), etc. fueron algunos de los profesores que participaron en esas iniciativas. En los últimos 20 años del siglo XXI la pedagogía del cine y su dimensión social se ha llevado en España a festivales como la Semana Internacional de Cine de Valladolid (SEMINCI) y la Muestra Europea de Cine de Segovia (MUCES).

\subsection{La contribución desde los entornos académicos}

A finales de los años noventa, el Grupo Comunicar funda la Revista Iberoamericana de educomunicación del mismo nombre. Una publicación que a lo largo de los años ha dado cabida a trabajos de gran nivel que han reflexionado sobre la pedagogía del cine, de la imagen y de las Tecnologías de la Información y de la Comunicación. Hay que destacar el número monográfico de "Comunicar" sobre cine del que se citan varios artículos en este trabajo (Comunicar 35, XVIII, «Lenguajes fílmi- 
cos sobre la memoria colectiva de Europa», publicado en el segundo semestre de octubre de 2010). Fundada por Ignacio Aguaded, Comunicar ha dado cabida a los trabajos de centenares de investigadores europeos y de toda América.

Unos años antes de la fundación del Grupo Comunicar, el Centro de Medios Audiovisuales de la UNED, lanzó de manera pionera el Curso de iniciación a la lectura de la imagen y al conocimiento de los medios audiovisuales (Aparici et al., 1987). Un equipo de jóvenes técnicos y profesionales diseñaron y produjeron el primer multimedia de pedagogía de la imagen con el objetivo de formar a profesores de todos los niveles educativos en los lenguajes del cine y de otros medios audiovisuales y servir de vínculo para generar un intercambio fructífero de experiencias entre todo el profesorado participante.

Este diseño multimedia recogía las dos líneas de aprovechamiento didáctico que ya había abordado Geneviève Jacquinot (1977) en su libro «Image et pédagogie». Esta autora se refiere a las posibilidades de utilización educativa del cine desde dos orientaciones: la pedagogía de la imagen y la pedagogía con imágenes. Aborda la aproximación al lenguaje de la imagen, a su técnica y a sus valores estéticos, pero sobre todo se refiere a las posibilidades del cine como instrumento didáctico.

Desde 1984 numerosos especialistas se han referido a las posibilidades expresivas, formativas y educativas del cine en nuestro país (Amar-Rodríguez, 2003; Canga, 2019; del-Amo, 1987; de-Pablos-Pons, 1986; Ferrés, 2014; Monterde, 1986; Pérez-Rodríguez \& Delgado-Ponce, 2012; Zunzunegui, 1984). A nivel internacional, en el ámbito anglosajón, diversos especialistas han abordado problemas estructurales similares a los encontrados en España a la hora de integrar la educación en el cine dentro del sistema educativo desde una perspectiva crítica (Masterman, 1993) o de plantear la continuidad de este tipo de enseñanza (Bazalgette, 2010).

Desde la segunda década del siglo XXI las nuevas formas de expresión, heredadas del lenguaje cinematográfico han comenzado a tomar carta de naturaleza, como es el caso de los videojuegos (Zagalo, 2010), o la animación 3D y la educación, pero estas derivas tienen importancia suficiente como para abordar una serie de ponencias con entidad en sí mismas. El Mercado del Vídeo 3D Wire que se celebra anualmente en la ciudad de Segovia, permite analizar un mundo que abre las puertas de la industria audiovisual en su conjunto a establecer nuevos desarrollos útiles para la educación. Diseños multimedia, estrategias transmedia, deben reconocer la vigencia del medio cine, como el origen de todo y la base para afrontar cualquier otro tipo de desarrollos tecnológicos.

\subsection{El cine como difusor de cultura y de pensamiento crítico}

Uno de los pioneros españoles de más larga trayectoria en la explotación didáctica del cine, Enrique Martínez-Salanova (2010), ha descrito las experiencias de construcción de una sensibilidad europea a través de la historia de este medio y de las inmensas potencialidades para poder experimentar con el cine la importancia de los valores ciudadanos.

El cine es en sí mismo un medio idóneo para la adquisición de cultura. Un medio que ha permitido a muchas personas aproximarse a la contemplación del arte y a la lectura de obras literarias adaptadas por algunos de los más grandes directores de la historia del cine: Welles, Truffaut, Huston, Pasolini, Visconti, Hitchcock han adaptado a autores como Shakespeare, Bradbury, Melville, Bocaccio, Mann o Hamilton. En el caso del cine español todavía resultan de imprescindible consulta, entre otras muchas, películas como "Los Santos Inocentes" (1984, basada en la obra homónima de Miguel Delibes y dirigida por Mario Camus) "Esquilache" (Molina,1989), basada en la obra de Buero Vallejo; «Un Soñador para un Pueblo» producida por Josefina Molina o «El Perro del Hortelano» (1996), adaptación de Pilar Miró del clásico teatral de Lope de Vega.

Además, a lo largo de los últimos años se han editado diferentes publicaciones (Prats, 2005), que recogían selecciones de películas para ser explotadas desde una perspectiva educativa con títulos relacionados con el cine para la educación (Marzábal \& Arocena, 2016). Y, más recientemente, la Academia Española del Cine (AACCE) ha impulsado la iniciativa oficial de hacer una selección de películas que se consideran especialmente dirigidas a la educación (Lara et al., 2018). El libro incluye una selección de títulos de cine español de diferentes épocas, con unas orientaciones amplias que consideran al cine arte, industria y fundamentalmente producto cultural.

En las reuniones para la preparación de esta publicación, estuvieron presentes profesionales de la producción, la exhibición y la distribución, académicos vinculados con diferentes oficios y profesionales de la educación de diferentes niveles educativos. La propia selección de títulos permite deducir cómo los debates para sacar adelante este listado reflejaron las diferentes concepciones de cómo el cine puede servir como mero instrumento de ocio o para estimular el pensamiento crítico de los espectadores más jóvenes. Una de las principales dinamizadoras de este debate, la profesora Mercedes Ruiz, del colectivo Cero en Conducta, mantiene el reto de crear puentes entre los productores, directores y exhibidores y el sistema escolar, para que los centros educa- 
tivos puedan programar cine y los escolares asistan a su vez a repoblar las salas cinematográficas.

\subsection{De la pedagogía del cine al cine social.}

Más allá de los listados de películas de distintos géneros que puedan considerarse idóneos para difundir literatura o para incorporarse de modo transversal en los entornos educativos formales como vía de reflexión sobre realidades sociales diversas, cabría mencionar aquí la utilización que se hace del medio en el marco específico de la comunicación con fines sociales. Nos referimos por un lado al llamado "cine social», un cine que, ya sea ficción o documental, da predominancia a fines de denuncia y/o concienciación social, en función de la implicación del director. Pone las historias y situaciones que representa al servicio de un determinado fin social, incitando con ello la reflexión por parte del espectador sobre determinadas problemáticas.

Por otro lado, habría que tender a la adquisición del compromiso integral de la industria cinematográfica en pro del giro necesario que todo el sistema mediático debe dar para alinearse con la necesaria transformación de las sociedades contemporáneas, tal como se propone desde la Comunicación con Fines Sociales. Ese giro podría iniciarse abriendo una reflexión interna en el sector sobre la necesidad de revertir las inercias que perpetúan, por ejemplo, el sexismo, la estereotipia y la desigualdad en las representaciones y en el acceso a los puestos de mayor responsabilidad; o sobre las consecuencias negativas de la extensión digital del acceso a géneros como el porno.

En este mismo marco, cabría incluso extender el medio cinematográfico desde su adaptación a las nuevas tecnologías, a toda la ciudadanía y, en particular, a personas que viven en situaciones o contextos de exclusión, para que mediante su apropiación se conviertan en creadores y productores de sus propias historias, dando el salto de receptores a creadores, tal como preveía la utopía de la red global. Para lo que sería imprescindible la educomunicación.

\section{EL VALOR DEL CINE EN ENTORNOS DE EXCLUSIÓN SOCIAL: EL CASO DE LAS PRISIONES}

Gran parte de las iniciativas aquí mencionadas ponen el énfasis en el valor del cine como medio cultural que aborda sus posibilidades específicas para analizar los grandes temas que preocupan al ser humano, a la historia de la humanidad, a personajes que han representado unos determinados valores y a los gran- des problemas que han influido en el devenir de nuestra civilización. Sin embargo, nos interesa aquí de modo específico lo que ese poder puede hacer en entornos concretos que, como en las instituciones penitenciarias, y pese a la obviedad de que la labor educativa debería ser en ellas nuclear, no acaba de asumirse como un verdadero compromiso, e incluso se está produciendo lo que Gil Cantero ha llamado una desprofesionalización educativa (Gil-Cantero, 2010). Uno de los ámbitos donde la función del cine ha cobrado mayor significación simbólica es el de las prisiones (Contreras-Pulido, 2014). Las experiencias en el ámbito penitenciario han demostrado cómo el cine puede ser un instrumento imprescindible para colaborar en la reinserción de los internos. Es a su vez una función liberadora en el sentido freiriano, dado que la población reclusa, al menos en España, se compone fundamentalmente de personas que no han tenido oportunidades, pobres, extranjeros, personas de bajo nivel de formación y escasas oportunidades de acceso a la cultura. El porcentaje de personas encarceladas por los delitos más graves, asesinatos o violaciones, representa un porcentaje en torno al $13 \%$ del total. Esta realidad se ilustra con datos significativos y nos permite demostrar cómo el cine puede ser uno de los pocos recursos accesibles para una población a la que se le ha negado tradicionalmente el contacto con el mundo exterior, con medios de comunicación como la prensa $\mathrm{y}$, actualmente como Internet y, por supuesto, cualquier acceso a las redes sociales. Esto nos lleva a describir cómo el cine es un medio de intervención que puede contribuir significativamente en los procesos de reinserción de las personas que cumplen condenas de privación de libertad.

\subsection{El taller cine en la Cárcel de Topas (Salamanca). El cine como espacio de libertad.}

El cine construye nuestro imaginario colectivo sobre la cárcel moderna. Y lo construye tan poderosamente, que sus modelos de representación contribuyen a la estigmatización de las personas presas, de los lugares de encierro y de todos los operadores jurídicos que intervienen en la imposición del castigo.

Son tan poderosos estos modelos de representación y han tenido tanta fuerza en nuestros imaginarios, que hasta las personas que cumplen condena de privación de libertad, distinguen en sus testimonios entre la cárcel real y la cárcel de la ficción.

Cuando entras, tienes la imagen de la cárcel de las películas. Lo primero que haces cuando comunicas es contar a tus padres que esto no es como en las películas. La cárcel de las películas no es la cárcel real. 
Hemos invisibilizado el castigo y sus formas y, al hacerlo, hemos dejado que sea el imaginario quien construya al castigado. Hemos ocultado el espacio en el que se cumple la pena y de esta forma, hemos contribuido a su mitificación. De tal manera se han imbricado realidad y ficción en los modelos de comunicación que han abordado los problemas de las personas en conflicto con la ley, que resulta cada vez más difícil explicar fuera del contexto de la cárcel real, que la cárcel de la ficción no es más que una representación interesada y espectacularizada de la realidad.

Los actuales modelos de representación de la exclusión social contribuyen poderosamente a su estigmatización. Lo dicen ellos y ellas, personas privadas de libertad que han participado durante los últimos diez años en los talleres de educomunicación que se han impartido en el Centro Penitenciario de Topas (Salamanca).

Para llegar a esta conclusión, iniciaron su proceso de alfabetización audiovisual analizando los modelos de representación que gran parte de los periódicos utilizan en la descripción de las personas en conflicto con la ley y cómo estos modelos inciden negativamente tanto en sus vidas antes, durante y después de sus condenas, como en las biografías de sus familias, dificultando aún más sus posibilidades de desarrollo cultural y económico, afectando incluso a los lugares en los que residen, favoreciendo los procesos de creación de guetos.

Cuando "comunicar" es casi tan importante como respirar, cuando se esperan semanas para "comunicar" y cuando la comunicación es sinónimo de contacto con la familia, con los seres queridos y con los relatos que nos apuntalan como individuos sociales, la comunicación se torna esencial en los procesos de reinserción social.

El taller de prensa era un proceso grupal, dialógico y crítico, no exento de dificultades ante la disparidad de culturas e idiomas, que facilitó la aproximación a un concepto de comunicación inclusiva que promueve proyectos participativos y democráticos de convivencia. En un principio los integrantes del taller entendían que este modelo de comunicación no era más que un ideal. La educomunicación como parte esencial de un proceso de toma de conciencia en que el derecho a la información deja de ser un ideal y es concebido como un derecho esencial.

El taller de cine tiene su origen en la radio del Centro Penitenciario. La radio es una herramienta fundamental para desarrollar las habilidades básicas de comunicación incluso en los contextos más radicales de exclusión social. Radio Libertad, que así es como se llama la Radio del Centro Penitenciario de Topas, contribuyó a pasar de la lectura a la escritura, de leer noticias a comentarlas e incluso a reescribirlas para adaptarlas al medio y favorecer su difusión y comprensión. Convencidos de que otra comunicación es posible, la radio se convertía por unas horas en lugar de encuentro. En la sección de cine y televisión, dos tardes a la semana se comentaba la programación y se recomendaban las películas de las distintas cadenas generalistas.

Así surge el taller de cine. Por iniciativa de los participantes en el taller de radio.

Nuestra metodología en el taller de cine es básica y parte de los principios de la comunicación para el cambio social: Horizontalidad, participación, colectividad (Marí, 2011) Dialogo para alcanzar los consensos básicos y mucha pasión por el cine.

Hemos visto centenares de películas que nos han servido para dialogar sobre conceptos como el amor, la muerte o la violencia.

Convertimos las dificultades con el idioma de quienes participan, en un ejercicio de sinopsis y de ayuda mutua y los inconvenientes que el reglamento penitenciario impone a las actividades de tratamiento, -nos obliga a partir la proyección en dos partes- en oportunidades para el desarrollo de nuestras habilidades básicas de comunicación. Resumir y recordar lo esencial de lo visto la semana anterior es una buena disculpa para intercambiar puntos de vista e incluso interpretaciones.

En cada sesión participan una media de treinta internos que provienen de una veintena de países distintos. ¿alguien duda del poder de la imagen para unir culturas? Y cada participante con una biografía tan rica y diversa en experiencias que nos ha permitido ver Moby Dick comentada por alguien que había estado embarcado en un ballenero. Visionar "Cuando todo está perdido" comentada por una persona que había naufragado dos veces y las dos veces había sido dada por muerta. ¿alguien duda del poder del relato cinematográfico para hacer que la ficción nos hable con la voz de la realidad? La lista de ejemplos y filmes sería interminable.

Imaginar en libertad es la sensación que comparten quienes participan en el taller de cine y quizá éstas sean suficientes razones para incluir los talleres de cine como parte imprescindible de los programas de tratamiento.

"El cine en la cárcel abre una venta de libertad" .El cine te quita cárcel como te la quita soñar".

El taller de cine es un lugar de encuentro. "La mesa camilla y el salón de nuestra casa”. La gran pantalla funcionando como un juego de espejos en el que vemos y nos vemos reflejados, y en esa identificación o en ese extrañamiento, construimos nuestra percepción del "otro" y sin eludir el conflicto, reflexionamos sobre nuestras propias vidas.

La educomunicación como parte de la estrategia de tratamiento penitenciario ya tiene un corpus académi- 
co extenso. Los máximos representantes de la disciplina avalan con sus estudios los beneficios de estas prácticas y reclaman desde hace muchos años su puesta en marcha como "aliados en los procesos de inclusión social" (Contreras-Pulido, 2014).

Las personas privadas de libertad que han participado en los talleres de cine saben que la educomunicación no va a suponer -por si misma- inclusión social. Son conscientes de que la exclusión social responde a procesos mucho más radicales y complejos. Pero saben que, sin el reconocimiento efectivo de su derecho a la educomunicación, sus procesos de integración como ciudadanos de pleno derecho serán más difíciles tanto para ellos como para sus familias.

\section{CUESTIONES PARA LA DISCUSIÓN}

¿Por qué hasta ahora, las instituciones educativas, las instituciones culturales y la industria del cine no han creado puentes sólidos para promover el aprovechamiento social, educativo y cultural del cine? ¿Cómo recoger las numerosas experiencias desarrolladas tanto en España como a nivel internacional, que representan buenas prácticas de explotación didáctica del cine en beneficio de la educación, de la cultura y de la propia industria del cine y de sus profesionales? ¿Hasta qué punto cobra vigencia en el actual contexto digital la actualización de una pedagogía del cine que vincule a los estudiantes de todos los niveles educativos con las facetas artísticas, creativas e industriales de este medio audiovisual? ¿Por qué no generalizar la utilización del cine para tareas de reinserción social consagradas por la Constitución española, como medio para el fomento de una educación liberadora?

\section{CONCLUSIONES}

Las experiencias de aprovechamiento educativo y cultural del cine en España tienen una trayectoria de más de 60 años. Esto indica que en ese largo recorrido la existencia de buenas prácticas marca un camino a seguir para proyectos institucionales más ambiciosos e integradores. Esa explotación didáctica y cultural del cine debe realizarse no solo con objetivos educativos definidos, sino también como un mecanismo de acceso a una comunicación, como diría Paulo Freire "concientizadora". Esto permitirá motivar a estudiantes que, a veces quedan fuera del sistema escolar y también a un elevado porcentaje de la población que no ha tenido las mismas oportunidades de acceso a la cultura. Es imprescindible que la relación entre el sistema educativo y la industria del cine se plasme en alianzas de mutua colaboración. La importancia de los saberes transversales aportados por el cine son la base de un conocimiento más informado sobre los contenidos imprescindibles para tener un comportamiento crítico frente a las múltiples pantallas que forman parte del actual ecosistema digital. Un mejor conocimiento del lenguaje cinematográfico es un paso imprescindible para una buena dieta mediática y una forma idónea para generar debates que eduquen en tolerancia y en una mejor comprensión del mundo.

\section{REFERENCIAS}

Alonso, M., \& Matilla, L. (1980). Imágenes en libertad. Nuestra Cultura.

Amar-Rodríguez, V. (2003). Comprender y disfrutar del cine. La gran pantalla como recurso educativo. Grupo Comunicar. https://bit.ly/3d0OMoi (ver. 01.04.2021).

Amo, C. (1987) Cine didáctico. Madrid. Instituto Nacional de Ciencias de la Educación.

Aparici, R., García-Matilla, A., Fernández-Baena, J., \& Osuna, S. (2006). La imagen. UNED.

Aparici, R., García-Matilla, A., \& Valdivia, M. (1987). Curso Multimedia de Iniciación a la lectura de la imagen y al conocimiento de los medios audiovisuales. UNED.

Bazalgette, C. (2010). El apagón analógico: El British Film Institute y la educación en los tres últimos decenios. Comunicar, 35(18), 15-24. https://doi.org/10.3916/ c35-2010-02-01

Bellido, A. (1993). El cinema y la televisió. Generalitat Valenciana.

Canga, M. (2019). Fundamentos de teoría de la imagen. Síntesis.

Contreras-Pulido, P. (2014). La alfabetización como herramienta de intervención en prisión. [Unpublished doctoral dissertation]. Universidad de Huelva. https://bit.ly/2ApTNcM (ver. 01.04.2021).

Eisenstein, S.M. (1957). Teoría y técnicas cinematográficas. Rialp.

Fernández, C. (1979). Iniciación al lenguaje del Cine. Ministerio de Cultura. Dirección General de Cine.

Ferrés, J. (2014). Las pantallas y el cerebro emocional. Gedisa.

García-Maroto, E. (1988). Aventuras y desventuras del cine español. Plaza y Janés.

González, M., \& Vázquez-Freire, M. (1986). O ensino da imaxe en Galicia. Unha experiencia interrompida. Revista Gallega de Educación, 2, 3-12.

Jacquinot, G. (1977). Image et pedagogie. PUF. 
Lara, F., Ruiz, M., \& Tarín, M. (2018). Cine y educación. Academia de las Artes y de las Ciencias Cinematográficas de España.

Marí, V. (2011). Comunicar para transformar, transformar para comunicar. Tecnologías de la información desde una perspectiva de cambio social. Editorial Popular.

Martinez-Salanova, E. (2002). Aprender con el cine. Aprender de película. Grupo Comunicar ediciones.

Martínez-Salanova, E. (2010). Los sistemas educativos en la memoria heterodoxa del cine europeo. Comunicar, 35, 53-60. https://doi.org/10.3916/c35-2010-02-05

Marzábal, I., \& Arocena, C. (2016). Películas para la educación. Cátedra.

Masterman, L. (1993). La revolución de los medios audiovisuales. De la Torre.

Mendo, M.A., Del-Río, P., Ródenas, J.M., \& Sanz-Agüero, M. (1975). Educación en la imagen. ESCO-CIFEJ.

Monterde, J.E. (1986). Cine, historia y enseñanza. Cuadernos de Pedagogía/Laia.

Monterde, J.E., Selva, M., \& Solá, A. (2002). La representación cinematográfica de la historia. Akal.

De-Pablos-Pons, J.M. (1986). Cine y enseñanza. Centro de Publicaciones del MEC/CIDE.

Pérez-Rodríguez, M.A., \& Delgado-Ponce, A. (2012). De la competencia audiovisual y digital a la competencia mediática: Dimensiones e indicadores. [From digital and audiovisual competence to media competence: Dimensions and indicators]. Comunicar, 39, 25-34. https://doi.org/10.3916/c39-2012-02-02

Pérez-Millán, J.A. (2014). Cine, enseñanza y enseñanza del cine. Morata.

Porter-Moix, M. (1964). Cinema per a infants. Nova Terra.

Prats, L.l. (2005). Cine para educar. Guía de más de 200 películas con valores. Bellacqua.

Rey, L.L., \& Maquinay, A. (1984). Cinema a l'escola. Casal del Mestre.

SOAP (ed.) (1972). El cine en la escuela. Servicio de Orientación de Actividades para-escolares (SOAP).

Stahelin, J.M. (1981). Introducción genética del cine: De Altamira al Winetrgarten. Secretariado de Publicaciones de la Universidad de Valladolid.

Vázquez-Freire, M. (1995). Pe de Imaxe: Catro anos de pedagoxía da imaxe. Eduga, 8, 123-131.

Zagalo, N. (2010). Alfabetización creativa en videojuegos: comunicación interactiva y alfabetización cinematográfica. Comunicar, 18(35), 61-68. https://doi. org/10.3916/c35-2010-02-06

Zunzunegui, S. (1984). Mirar la imagen. Universidad del País Vasco. 